\title{
PENGARUH DISIPLIN, PROFESIONALISME DAN KARAKTERISTIK GURU TERHADAP KINERJA GURU SEKOLAH DASAR (SD) Se-KECAMATAN STABAT KABUPATEN LANGKAT
}

\author{
Sagino \\ Universitas Islam Sumatera Utara \\ Sagino.mm@gmail.com
}

\begin{abstract}
The problem formulation in this research is: how to influence the discipline on the teacher's performance, how the professional influence on the teacher's performance in elementary School (SD) Se - District Stabat Langkat District. How the teacher's characteristic influence on the teacher's performance in elementary School (SD) Se - Kecamatan Stabat, Langkat District, how to simultaneously influence the discipline, professionalism and characteristics of teachers on teachers ' performance in elementary School (SD) Se - District of Stabat, Langkat district. The results of the study were obtained that there was a significant influence on the discipline variable impact master performance with the value of Thitung > This (4,708 > 1,995). Professionalism variable has a significant effect on Guru performance with the value of Thitung > This (2,391 > 1,995), characteristic variables have significant effect on Guru performance with the value of Thitung > This (3,988 > 1,995), discipline variables, Professionalism, the characteristics of positive and significant effect on the performance of teachers in elementary School (SD) Se-Kecamatan Stabat District Langkat. Of $41.3 \%$, while the remaining of $58.7 \%$ (100\%-41.3\%) Influenced by other factors not researched.
\end{abstract}

Keyworld: discipline, professionalism, characteristics and Teacher Performance

ABSTRAK : Rumusan masalah dalam penelitian ini adalah : Bagaimana pengaruh disiplin terhadap kinerja guru, bagaimana pengaruh profesionalisme terhadap kinerja guru di Sekolah Dasar ( SD ) Se - Kecamatan Stabat Kabupaten Langkat. bagaimana pengaruh karakteristik guru terhadap kinerja guru di Sekolah Dasar ( SD ) Se - Kecamatan Stabat Kabupaten Langkat, bagaimana pengaruh disiplin, profesionalisme dan karakteristik guru secara simultan terhadap kinerja guru di Sekolah Dasar ( SD ) Se - Kecamatan Stabat Kabupaten Langkat. Hasil penelitian diperoleh bahwa ada pengaruh variable disiplin berpengaruh signifikan terhadap Kinerja Guru dengan nilai $t_{\text {hitung }}>t_{\text {tabel }}$ (4.708 > 1.995).Variabel profesionalisme berpengaruh signifikan terhadap Kinerja Guru dengan nilai $t_{\text {hitung }}>t_{\text {tabel }}(2.391>1.995)$, Variabel karakteristik berpengaruh signifikan terhadap Kinerja Guru dengan nilai $t_{\text {hitung }}>t_{\text {tabel }}(3.988>1.995)$, variabel disiplin, Profesionalisme, karakteristik berpengaruh positif dan signifikan terhadap kinerja guru di Sekolah Dasar (SD) Se-Kecamatan Stabat Kabupaten Langkat. sebesar 41.3\%, sedangkan sisanya sebesar 58.7\% (100\% - 41.3\%) dipengaruhi oleh faktor-faktor lain yang tidak diteliti.

Keyworld : Disiplin, Profesionalisme, Karakteristik dan Kinerja Guru

\section{Pendahuluan}

Kinerja guru merupakan elemen penting dalam pendidikan, selain itu juga merupakan penentu tinggi rendahnya kualitas pendidikan. Kinerja guru dilakukan oleh guru dalam melaksanakan tugas seorang guru sebagai pendidik. Kualitas kinerja guru sangat menentukan pada kualitas hasil pendidikan dikarenakan guru merupakan sosok yang paling sering berinteraksi secara langsung dengan siswa pada saat proses pembelajaran.
Guru merupakan komponen penting dalam dunia pendidikan, oleh karenanya perhatian yang lebih perlu diberikan agar dapat menciptakan guru yang berkualitas sehingga hal tersebut dapat menunjang kinerja guru. Guru juga memegang peran penting dalam dunia pendidikan khususnya dalam bidang formal disekolah,guru sangat menentukan keberhasilan peserta didik terutama dalam hal proses belajar mengajar yang biasa dilaksanakan di sekolah. 
Keberhasilan kinerja yang ditunjukan guru dipengaruhi oleh lingkungan sekitarnya. Oleh karena itu lingkungan sekitar khususnya dalam hal ini pihak sekolah semisal kepala sekolah yang mampu memotivasi serta memberdayakan guru agar tercipta kinerja yang baik serta mampu berperan sebagai guru yang professional disamping guru itu sendiri yang mampu meningkatkan kualitas kerjanya sendiri. Kinerja guru selama ini terkesan kurang optimal. Guru melaksanakan tugasnya hanya sebagai kegiatan rutin, kurang kreativitas. Inovasi bagi guru relatif tertutup dan kreativitas bukan merupakan bagian dari prestasi (Sagala, 2015 : 38). Kinerja Guru dalam lembaga pendidikan merupakan persoalan yang krusial dan mengharuskan setiap lembaga melakukan penataan dan pembenahan sesuai dengan dimensi ruang dan waktu. Terlebih-lebih bagi lembaga pendidikan yang ditunjuk untuk menjalankan tugas pokok dan fungsinya secara disiplin dan tepat waktu. Tuntutan ini menjadi kecenderungan global yang mau tidak mau, suka tidak suka, harus dipenuhi guna menyelaraskan kinerja Guru di dalam lembaga pendidikan, yang mengakselerasi perubahan eksternal dengan mengunakan berbagai pendekatan. Upaya pembenahan kinerja Guru dalam lembaga pendidikan terus dilakukan dengan cara, antara lain adalah meningkatkan kualitas Guru, meningkatkan kemampuan sumber daya manusia dalam memecahkan berbagai masalah dan tumbuhnya responsibilitas lembaga pendidikan terhadap persoalan dan tuntutan dari dalam lembaga pendidikan itu sendiri maupun dari luar.

Ada beberapa faktor penting yang berpengaruh terhadap meningkatnya kinerja guru, yaitu disiplin kerja guru. Disiplin kerja sering terabaikan dikalangan guru. Hal ini dapat dilihat dari beberapa contoh antara lain: kedatang ke sekolah terlambat, tidak berada di sekolah pada jam kerja, menunda pekerjaan, pulang sebelum waktunya dan lain-lain. Bagi mereka yang terpenting adalah mengisi daftar hadir. $\mathrm{Hal}$ demikian ini secara tidak langsung akan mempengaruhi prestasi kerja guru. Hal ini terbukti dengan sedikitnya guru yang memperoleh kenaikan pangkat pilihan, penghargaan maupun promosi jabatan secara fair (Simamora: 2010:12). Disiplin dalam mengajar juga sangat penting artinya bagi guru. Karena itu, kedisiplinan harus ditanamkan secara terus menerus kepada guru. Penanaman yang terus menerus menyebabkan disiplin tersebut menjadi kebiasaan bagi guru. Orang-orang yang berhasil dalam bidangnya masing-masing, pada umumnya mempunyai kedisiplinan yang tinggi. Sebaliknya orang yang gagal, umumnya tidak disiplin. Sesungguhnya masalah kedisiplinan ini menjadi perhatian bagi setiap manusia. Disiplin mempunyai peranan yang sangat penting dalam mengarahkan kehidupan manusia untukmeraih cita-citanya serta kesuksesan dalam bekerja, karena tanpa adanya kedisiplinan maka seseorang tidak mempunyai patokan tentang apa yang baik dan yang buruk dalam tingkah lakunya

Selain dipengaruhi oleh disiplin kerja kinerja guru juga dipengaruhi oleh profesionalisme, Pengembangan profesionalisme guru menjadi perhatian pemerintah secara khusus dengan adanya peraturan tentang standar pendidik dan tenagakependidikan (Peraturan Pemerintah RI nomor 19 tahun 2005 tentang Standar Nasional Pendidikan), karena guru dipandang memiliki tugas dan peranbukan hanya memberikan informasi ilmu pengetahuan dan teknologi, melainkan juga membentuk sikap dan jiwa yang mampu berta han dalam erahiperkompetisi. Sejalan dengan hal tersebut pengembangan prosespembelajaran yang dilaksanakan oleh guru harus memiliki srategipelaksanaan dalam tingkat satuan pendidikan meliputi: a) workshop, b) in hause training, c) supervisi d) kegiatan MGMP (Umiarso, 2010:342).

Guru sebagai tenaga professional seharusnya memiliki pengetahuan dan pengalaman di bidangnya. Guru yang memiliki pengetahuan dan pengalaman yang cukup dalam bidangnya akan mampu melihat ke depan dalam peningkatan perkembangan unit pelayanan teknis (UPT). Kinerja guru dapat dilihat dari penguasaan guru terhadap kompetensi yang dimiliki sebagai tenaga profesional.

Dalam pelaksanaan tugas mendidik, guru memiliki sifat dan perilaku yang berbeda, ada yang bersemangat dan tanggung jawab, dan ada guru yang melakukan pekerjaan itu tanpa dilandasi tanggung jawab, selain itu ada juga guru yang membolos, datang tidak tepat pada waktunya, dan tidak mematuhi perintah. Kondisi guru seperti itulah yang menjadi permasalahan disetiap lembaga pendidikan formal. Dengan adanya guru yang memiliki kinerja rendah, sekolah akan sulit mencapai hasil yang diharapkan.

Kinerja dalam menjalankan fungsinya tidak berdiri sendiri, melainkan selalu berhubungan dengan kepuasan kerja dan tingkat besaran imbalan yang diberikan, serta dipengaruhi oleh keterampilan, kemampuan, dan sifat- sifat individu. Setiap diri individu terhadap segala 
sesuatu yang ditetapkan kepadanya, akan menciptakan suatu masyarakat yang tertib dan bebas dari kekacauan. Demikian juga kehidupan dalam suatu organisasi akan sangat dibutuhkan ketaatan dari anggota-anggotanya pada peraturan dan ketentuan yang berlaku pada organisasi tersebut, karena apa yang mejadi tujuan dari organisasi akan sulit dicapai bila tidak ada disiplin kerja.

Namun sering kita lihat seorang guru menampilkan figur yang tidak semestinya sebagai seorang pendidik yang profe sional. Guru memiliki tempat tersendiri dalam masyarakat, karena fakta menunjukkan ketika guru berbuat menyimpang dari kaidah masyarakat dan menyimpang dari apa yang diharapkan masyarakat, masyarakat langsung memberikan suara sumbang kepada guru itu. Kenakalan anak yang menggejala diberbagai tempat, sering pula tanggungjawabnya ditudingkan kepada guru sepenuhnya dan sering pula dilupakan apa yang dilihat, didengar anak serta pergaulan anak dalam kehidupan masyarakat sehari-hari (Mulyasa, 2011:183).

Tugas guru adalah membantu peserta didik agar mampu beradaptasi terhadap berbagai tantangan kehidupan serta desakan yang berkembang dalam dirinya. Pemberdayaan peserta didik ini meliputi aspek-aspek kepribadian terutama aspek intelektua, sosial, emosional, dan keterampilan. Tugas mulia ini menjadi berat karena bukan saja guru harus menyiapkan generasi muda memasuki abad pengetahuan, melainkan harus mempersiapkan diri agar tetap eksis baik sebagai individu maupun sebagai profesional. Hal tersebut menunjukkan betapa strategis kedudukan guru dalam penyelenggaraan pendidikan, sehingga adanya standar yang harus dicapai oleh guru dalam melaksanakan kegiatan pembelajaran dalam meningkatkan komponen input, dan proses pembelajaran yang dilaksanakan akan lebih efektif sehingga hasil yang diharapkan lebih berfokus dan mengarah pada kondisi peserta didik dengan menentukan performence (Jamal, 2011: 64).

\subsection{Rumusan Masalah}

Sesuai dengan uraian yang telah di sebutkan di atas, maka rumusan masalah penelitian ini adalah : Bagaimana pengaruh disiplin, profesionalisme dan karakteristik guru secara simultan terhadap kinerja guru di Sekolah Dasar ( SD ) Se - Kecamatan Stabat Kabupaten Langkat.

\subsection{Batasan Masalah}

Batasan masalah dibatasin pada penelitian mengenai variabel disiplin, profesionalisme, karakteristik dan kinerja guru di Sekolah Dasar ( SD ) Se Kecamatan Stabat Kabupaten Langkat

\subsection{Hipotesis}

Hipotesis dalam penelitian ini melihat sejauh mana Disiplin, profesionalisme dan karakteristik guru berpengaruh secara simultan terhadap kinerja guru Sekolah Dasar ( SD ) Se-Kecamatan Stabat Kabupaten Langkat.

\subsection{Tujuan Penelitian}

Berdasarkan rumusan masalah penelitian sebagaimana diuraikan di atas, maka tujuan yang hendak dicapai dalam penelitian ini yaitu:

a. Untuk mengetahui pengaruh disiplin terhadap kinerja guru di Sekolah Dasar ( SD ) Se Kecamatan Stabat Kabupaten Langkat.

b. Untuk mengetahui pengaruh profesionalisme terhadap kinerja guru di Sekolah Dasar ( SD ) $\mathrm{Se}$ - Kecamatan Stabat Kabupaten Langkat.

c. Untuk mengetahui pengaruh karakteristik guru terhadap kinerja guru di Sekolah Dasar ( SD ) Se - Kecamatan Stabat Kabupaten Langkat.

d. Untuk mengetahui pengaruh disiplin, profesionalisme dan karakteristik guru secara simultan terhadap kinerja guru di Sekolah Dasar ( SD ) Se - Kecamatan Stabat Kabupaten Langkat.

\section{Metode Penelitian}

\subsection{Populasi dan Sampel}

Populasi adalah wilayah generalisasi yang terdiri atas objek/subjek yang mempunyai kualitas dan karakteristik tertentu yang ditetapkan oleh peneliti untuk dipelajari kemudian ditarik kesimpulannya ( Sugiyono, 2010:12). Populasi dalam penelitian ini adalah guru Sekolah Dasar ( SD ) Se-Kecamatan Stabat Kabupaten Langkat. 
Tabel 1. Kerangka Populasi Berdasarkan Status Guru TP. 2018/2019

\begin{tabular}{|c|l|c|c|c|}
\hline \multirow{2}{*}{ No } & \multirow{2}{*}{ Jabatan } & \multicolumn{2}{|c|}{ Status Guru } & \multirow{2}{*}{ Jumlah } \\
\cline { 3 - 4 } & & PNS & $\begin{array}{c}\text { Non } \\
\text { PNS }\end{array}$ & \\
\hline 1 & SDN 050659 Stabat & 16 & 2 & 18 \\
\hline 2 & SDN 050666 Lubuk Dalam & 10 & 10 & 20 \\
\hline 3 & SDN 050662 Perdamaian & 13 & 8 & 21 \\
\hline 4 & SDN 056001 Karang Rejo & 11 & 7 & 18 \\
\hline \multicolumn{2}{|c|}{ Jumlah } & $\mathbf{5 0}$ & $\mathbf{2 7}$ & $\mathbf{7 7}$ \\
\hline
\end{tabular}

Sumber: Dinas Pendidikan Bidang Pembinaan SD DISDIK Langakat

Dalam penelitian ini penulis menggunakan teknik Purposive Random Sampling, yaitu teknik penentuan sampel dengan pertimbangan tertentu artinya setiap subjek yang diambil dari populasi dipilih dengan sengaja berdasarkan tujuan dan pertimbangan tertentu (Sugiyono, 2010:131 ). Kriteria penentuan sampel didasarkan pada subjek yang aktif dalam mengikuti kegiatan $\mathrm{KKG}$

Tabel 2. Kerangka Sampel Berdasarkan Status Guru TP. 2018/2019

\begin{tabular}{|c|c|c|c|c|}
\hline \multirow{3}{*}{ No } & \multirow[b]{3}{*}{ Jabatan } & \multirow{2}{*}{\multicolumn{2}{|c|}{ Status Guru }} & \multirow[b]{3}{*}{ Jumlah } \\
\hline & & & & \\
\hline & & PNS & $\begin{array}{l}\text { Non } \\
\text { PNS }\end{array}$ & \\
\hline 1 & SDN 050659 Stabat & 16 & 2 & 18 \\
\hline 2 & SDN 050666 Lubuk Dalam & 10 & 10 & 20 \\
\hline 3 & SDN 050662 Perdamaian & 13 & 8 & 21 \\
\hline 4 & SDN 056001 Karang Rejo & 11 & 7 & 18 \\
\hline \multicolumn{2}{|r|}{ Jumlah } & 50 & 27 & 77 \\
\hline
\end{tabular}

Sumber: Dinas Pendidikan Bidang Pembinaan SD DISDIK Langkat

\subsection{Uji Normalitas Data}

Uji normalitas adalah untuk melihat apakah nilai residual terdistribusi normal atau tidak. Model regresi yang baik adalah memiliki nilai residual yang terdistribusi normal. Jadi uji normalitas bukan dilakukan pada masing-masing variabel tetapi pada nilai residualnya. Sering terjadi kesalahan yang jamak yaitu bahwa uji normalitas dilakukan pada masing-masing variabel. Hal ini tidak dilarang tetapi model regresi memerlukan normalitas pada nilai residualnya bukan pada masing-masing variabel penelitian. Pengujian normalitas data penelitian adalah untuk menguji apakah dalam model statistik variabel-variabel penelitian berdistribusi normal atau tidak normal. Model regresi yang tinggi adalah memiliki distribusi normal atau mendekati normal. Untuk menguji apakah distribusi data normal atau tidak, salah satunya dengan menggunakan metode gambar normal Probabilitas Plots digunakan untuk pada seluruh SD Se-Kecamatan Stabat Kabupaten Langkat dan di anggap dapat mewakili subjek yang tidak di jadikan populasi dalam penelitian ini. Aktifitas guru dalam mengikuti kegiatan KKG guru SD Se-Kecamatan Stabat Kabupaten Langkat dibuktikan dengan absensi kehadiran guru. menyimpulkan apakah model analisis memenuhi asumsi normal, dengan penyebaran data di sekitar garis diagonal dan mengikuti arah garis diagonal maka data tersebut mememenuhi asumsi normal dalam model analisis, yang dapat dilihat pada gambar dibawah ini :

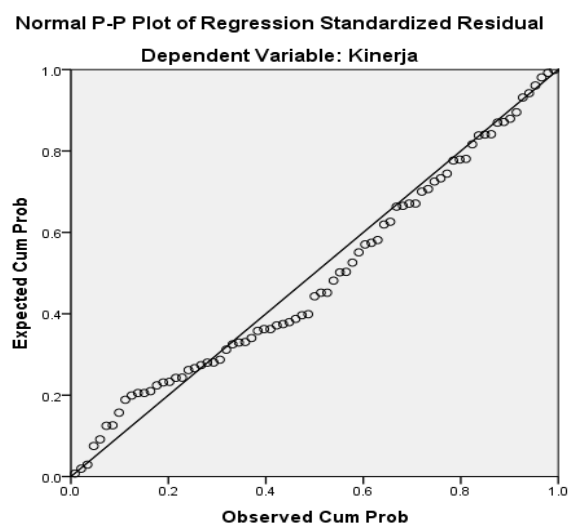

Gambar 1. Uji asumsi normalitas 


\subsection{Uji Multikolinearitas}

Multikolinieritas berati adanya hubungan yang kuat diantara beberapa atau semua variabel bebas pada model regresi. Jika terdapat multikolinieritas maka koefisien regresi menjadi tidak tentu, tingkat kesalahannya menjadi sangat besar dan biasanya ditandai dengan koefisien determinasi yang sangat besar tetapi pada pengujian parsial koefisien regresi, tidak ada atau pun kalau ada sangat sedikit sekali koefisien regresi yang signifikan. Pada penelitian ini digunakan nilai Variance Inflantion Factorrs (VIF) sebagai indikator ada tidaknya multikolinearitas di antara variabel bebas.

Tabel 3. Uji asumsi multikolinieritas Coefficients $^{\mathrm{a}}$

\begin{tabular}{|ll|r|r|}
\hline \multirow{2}{*}{ Model } & \multicolumn{2}{|c|}{ Collinearity Statistics } \\
\cline { 2 - 3 } & Tolerance & \multicolumn{1}{c|}{ VIF } \\
\hline 1 & (Constant) & & \\
& Disiplin & .941 & 1.063 \\
& Profesionalisme & .940 & 1.064 \\
Karakteristik & .999 & 1.001 \\
\hline
\end{tabular}

a. Dependent Variable: Kinerja

Berdasarkan nilai VIF yang diperoleh seperti terlihat pada tabel 3 diatas sebesar 1.063, 1.064, dan 1.001 dengan nilai tolerance 0.941, 0.940, dan 0.999, hal ini menunjukkan adanya korelasi yang cukup tinggi/kuat antara sesama variabel bebas, dimana nilai VIF dari keempat varibel bebas lebih kecil dari 10 dan dapat disimpulkan tidak terjadi multikolinieritas diantara keempat variabel bebas tersebut.

\subsection{Uji Heteroskedastisitas}

Pada output SPSS di bagian Scatterplot, terlihat titik-titik menyebar secara acak, tidak membentuk sebuah pola tertentu yang jelas, serta tersebar baik diatas maupun dibawah angka nol pada sumbu Y. Hal ini berarti tidak terjadi heteroskedastisitas pada model regresi, sehingga model regresi layak dipakai, dan dapat dilihat pada Gambar 2. dibawah ini :

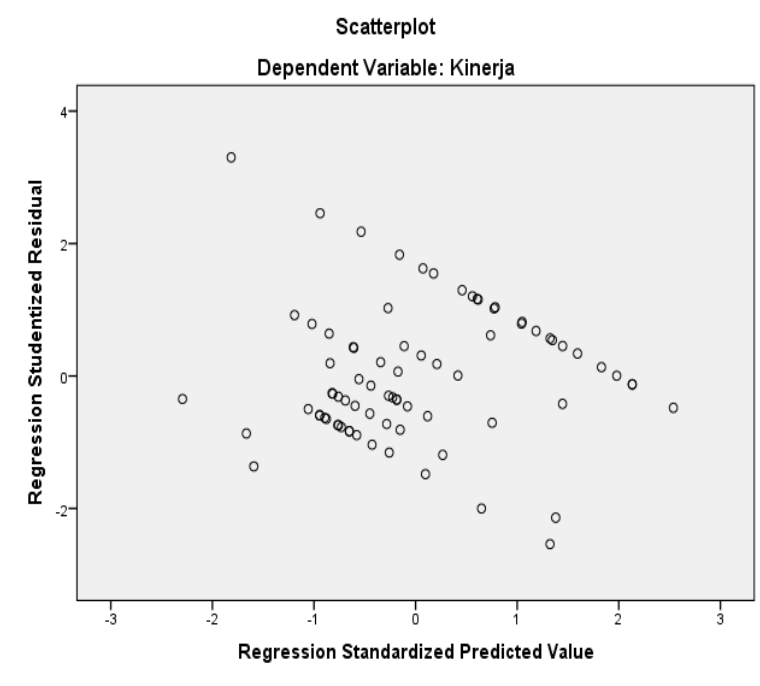

Gambar 2. Uji heterekedasitas

\section{Hasil dan Pembahasan}

\subsection{Analisis Regresi Linier Berganda}

Analisis regresi linier berganda antara Disiplin, Profesionalisme, Karakteristik Terhadap Kinerja Guru di Sekolah Dasar ( SD ) SeKecamatan Stabat Kabupaten Langkat., maka dapat dilihat dari persamaan regresinya, dan dari output SPSS diperoleh data sebagai berikut.

Tabel 4.. Hasil uji statistik koefisien regresi

Coefficients $^{\mathrm{a}}$

\begin{tabular}{|c|c|c|c|c|c|}
\hline \multirow[b]{2}{*}{ Model } & \multicolumn{2}{|c|}{$\begin{array}{c}\text { Unstandardized } \\
\text { Coefficients }\end{array}$} & \multirow{2}{*}{$\begin{array}{c}\text { Standardized } \\
\text { Coefficients }\end{array}$} & \multirow[b]{2}{*}{$\mathrm{t}$} & \multirow[b]{2}{*}{ Sig. } \\
\hline & B & Std. Error & & & \\
\hline $1 \quad$ (Constant) & 12.640 & 4.717 & & 2.680 & .009 \\
\hline Disiplin & .358 & .076 & .435 & 4.708 & .000 \\
\hline Profesionalisme & .151 & .063 & .221 & 2.391 & .019 \\
\hline Karakteristik & .259 & .065 & .358 & 3.988 & .000 \\
\hline
\end{tabular}

Berdasarkan Tabel 4 diatas dapat dibuat persamaan regresi sebagai berikut :

$$
\text { 4. } \mathrm{Y}=\begin{gathered}
12.640+0.358 X 1+0.151 X 2+ \\
0.259 X 3+\varepsilon
\end{gathered}
$$

Nilai Kinerja Guru di Sekolah Dasar ( SD ) Se-Kecamatan Stabat Kabupaten Langkat sebesar 12.640, yang mana nilai dari variabel disiplin, profesionalisme, karakteristik diabaikan.
Persamaan di atas menjelaskan bahwa koefisien regresi X1 (disiplin) mempunyai nilai positif yaitu 4.708 , hal ini menunjukkan bahwa variabel displin kerja mempunyai pengaruh positif terhadap Kinerja Guru di Sekolah Dasar ( SD ) Se-Kecamatan Stabat Kabupaten Langkat. Hal bila kerja meningkat 1\%, maka kinerja guru akan bertambah 47.0 . 
Koefisien regresi X2 (profesionalisme) mempunyai nilai positif yaitu 2.391, hal ini menunjukkan bahwa variabel profesionalisme kerja mempunyai pengaruh positif terhadap Kinerja Guru di Sekolah Dasar ( SD ) SeKecamatan Stabat Kabupaten Langkat. Hal bila kerja meningkat $1 \%$, maka kinerja guru akan bertambah 23.9.

Koefisien regresi X3 (Karakteristik) mempunyai nilai positif yaitu 3.988 , hal ini menunjukkan bahwa variabel karakteristik kerja mempunyai pengaruh positif terhadap Kinerja Guru di Sekolah Dasar ( SD ) Se-Kecamatan Stabat Kabupaten Langkat. Hal bila kerja meningkat $1 \%$, maka kinerja guru akan bertambah 39.8 .

\subsection{Hipotesis}

\subsubsection{Uji F (Uji Simultan)}

Tabel 5. Anova ${ }^{\mathrm{b}}$ pengaruh pengaruh Disiplin, Profesionalisme, Karakteristik terhadap kinerja guru ANOVA $^{\mathrm{a}}$

\begin{tabular}{|c|c|c|c|c|c|c|}
\hline \multicolumn{2}{|c|}{ Model } & $\begin{array}{l}\text { Sum of } \\
\text { Squares }\end{array}$ & $\mathrm{df}$ & Mean Square & $\mathrm{F}$ & Sig. \\
\hline \multirow[t]{3}{*}{1} & Regression & 281.264 & 3 & \multirow{3}{*}{$\begin{array}{r}93.755 \\
5.482\end{array}$} & \multirow[t]{3}{*}{17.102} & \multirow[t]{3}{*}{$.000^{\mathrm{b}}$} \\
\hline & Residual & 400.191 & 73 & & & \\
\hline & Total & 681.455 & 76 & & & \\
\hline
\end{tabular}

b. Predictors: (Constant), Karakteristik, Disiplin, Profesionalisme

Dari tabel 5 di atas diperoleh nilai $\mathrm{F}_{\text {hitung }}$ sebesar 17.102. Penelitian ini menggunakan taraf signifikansi $(\alpha: 0,05)$ dan Derajat Kebebasan (DK) dengan ketentuan numerator : jumlah variabel -1 atau $4-1=3$, dan jumlah sampel dikurang 2 atau $77-2=75$. Dengan ketentuan tersebut, diperoleh nilai $\mathrm{F}_{\text {tabel }}$ sebesar 2.730 . Dengan kriteria hipotesis sebagai berikut :

Jika $\mathrm{F}_{\text {hitung }}>\mathrm{F}_{\text {tabel}}$, maka $\mathrm{H} 0$ ditolak dan $\mathrm{Ha}$ diterima.

Jika $\mathrm{F}_{\text {hitung }}<\mathrm{F}_{\text {tabel}}$, maka $\mathrm{HO}$ diterima dan $\mathrm{Ha}$ ditolak.

Dari hasil perhitungan diperoleh nilai $\mathrm{F}_{\text {hitung }}>$ $F_{\text {tabel }}(17.102>2.730)$ dan nilai signifikasi 0.000 $<0.05$, sehingga H0 ditolak dan Ha diterima. Artinya ada pengaruh Disiplin, Profesionalisme, Karakteristik Terhadap Kinerja Guru di Sekolah Dasar ( SD ) Se-Kecamatan Stabat Kabupaten
Langkat. Dengan demikian model regresi ini sudah layak dan benar serta dapat disimpulkan bahwa variabel pengaruh Disiplin, Profesionalisme, Karakteristik secara simultan Terhadap Kinerja Guru di Sekolah Dasar ( SD ) Se-Kecamatan Stabat Kabupaten Langkat.

\subsubsection{Uji-t (Uji parsial)}

a. Pengaruh Disiplin Terhadap Kinerja Guru di Sekolah Dasar ( SD ) Se-Kecamatan Stabat Kabupaten Langkat

Untuk mengetahui pengaruh Disiplin kerja terhadap Terhadap Kinerja Guru di Sekolah Dasar (SD) Se-Kecamatan Stabat Kabupaten Langkat digunakan uji-t, sedangkan untuk melihat besarnya pengaruh digunakan angka Beta atau Standardized Coefficient.

Tabel. 6. Coeficients ${ }^{\mathrm{a}}$ pengaruh Disiplin terhadap Kinerja

Coefficients $^{\mathrm{a}}$

\begin{tabular}{|c|c|c|c|c|c|}
\hline \multirow[b]{2}{*}{ Model } & \multicolumn{2}{|c|}{$\begin{array}{c}\text { Unstandardized } \\
\text { Coefficients }\end{array}$} & \multirow{2}{*}{$\begin{array}{c}\text { Standardized } \\
\text { Coefficients } \\
\text { Beta }\end{array}$} & \multirow[b]{2}{*}{$\mathrm{t}$} & \multirow[b]{2}{*}{ Sig. } \\
\hline & $\mathrm{B}$ & Std. Error & & & \\
\hline $1 \quad \begin{array}{l}\text { (Constant) } \\
\text { Disiplin }\end{array}$ & $\begin{array}{r}12.640 \\
.358\end{array}$ & $\begin{array}{r}4.717 \\
.076\end{array}$ & .435 & $\begin{array}{l}2.680 \\
4.708\end{array}$ & $\begin{array}{l}.009 \\
.000\end{array}$ \\
\hline
\end{tabular}

Dari tabel 6 , diatas diperoleh nilai $t_{\text {hitung }}$ sebesar 4.708. Penelitian ini menggunakan taraf signifikansi $(\alpha: 0,05)$ dan Derajat Kebebasan (DK) dengan ketentuan DK $=\mathrm{n}-2$, atau $77-2=$ 75. Dengan ketentuan tersebut, diperoleh nilai $\mathrm{t}_{\text {tabel }}$ sebesar 1.995. Dengan kriteria hipotesis sebagai berikut :

Jika $t_{\text {hitung }}>\mathrm{t}_{\text {tabel }}$, maka $\mathrm{H}_{0}$ ditolak dan $\mathrm{H}_{\mathrm{a}}$ diterima.

Jika $\mathrm{t}_{\text {hitung }}<\mathrm{t}_{\text {tabel }}$, maka $\mathrm{H}_{0}$ diterima dan $\mathrm{H}_{\mathrm{a}}$ ditolak. 
Dari hasil perhitungan diperoleh nilai $\mathrm{t}_{\text {hitung }}>$ $\mathrm{t}_{\text {tabel }}(4.708>1.995)$ dan nilai signifikasi $0.000<$ 0.05, sehingga $\mathrm{H}_{0}$ ditolak dan $\mathrm{Ha}$ diterima. Artinya variabel Disiplin berpengaruh signifikan terhadap Kinerja Guru di Sekolah Dasar (SD) Se-Kecamatan Stabat Kabupaten Langkat. Besarnya berpengaruh signifikan terhadap Kinerja Guru di Sekolah Dasar (SD) SeKecamatan Stabat Kabupaten Langkat sebesar 4.708 atau $47 \%$.

\section{b. Pengaruh Profesionalisme Terhadap Kinerja Guru di Sekolah Dasar (SD) Se- Kecamatan Stabat Kabupaten Langkat}

Untuk mengetahui pengaruh Profesionalisme kerja terhadap Terhadap Kinerja Guru di Sekolah Dasar (SD) Se-Kecamatan Stabat Kabupaten Langkat digunakan uji-t, sedangkan untuk melihat besarnya pengaruh digunakan angka Beta atau Standardized Coefficient.

Tabel. 7. Coeficients ${ }^{\mathrm{a}}$ pengaruh Profesionalisme terhadap Kinerja

Coefficients $^{\mathrm{a}}$

\begin{tabular}{|c|c|c|c|c|c|}
\hline \multirow[b]{2}{*}{ Model } & \multicolumn{2}{|c|}{$\begin{array}{c}\text { Unstandardized } \\
\text { Coefficients }\end{array}$} & $\begin{array}{l}\text { Standardized } \\
\text { Coefficients }\end{array}$ & & \\
\hline & B & Std. Error & Beta & $\mathrm{t}$ & Sig. \\
\hline \begin{tabular}{|ll}
1 & (Constant) \\
& Profesionalisme
\end{tabular} & $\begin{array}{r}12.640 \\
.151\end{array}$ & $\begin{array}{r}4.717 \\
.063\end{array}$ & .221 & $\begin{array}{l}2.680 \\
2.391\end{array}$ & $\begin{array}{l}.009 \\
.019\end{array}$ \\
\hline
\end{tabular}

Dari tabel 7 diatas diperoleh nilai $t_{\text {hitung }}$ sebesar 2.391. Penelitian ini menggunakan taraf signifikansi $(\alpha: 0,05)$ dan Derajat Kebebasan (DK) dengan ketentuan $\mathrm{DK}=\mathrm{n}-2$, atau $77-2=$ 75. Dengan ketentuan tersebut, diperoleh nilai $t_{\text {tabel }}$ sebesar 1.995. Dengan kriteria hipotesis sebagai berikut :

Jika $t_{\text {hitung }}>\mathrm{t}_{\text {tabel }}$, maka $\mathrm{H}_{0}$ ditolak dan $\mathrm{H}_{\mathrm{a}}$ diterima.

Jika $\mathrm{t}_{\text {hitung }}<\mathrm{t}_{\text {tabel }}$, maka $\mathrm{H}_{0}$ diterima dan $\mathrm{H}_{\mathrm{a}}$ ditolak.

Dari hasil perhitungan diperoleh nilai $t_{\text {hitung }}>$ $\mathrm{t}_{\text {tabel }}(2.391>1.995)$ dan nilai signifikasi $0.000<$ 0.05 , sehingga $\mathrm{H}_{0}$ ditolak dan $\mathrm{Ha}$ diterima. Artinya variabel profesionalisme berpengaruh signifikan terhadap Kinerja Guru di Sekolah

Tabel. 8. Coeficients ${ }^{\mathrm{a}}$ pengaruh Karakteristik terhadap Kinerja

Coefficients $^{\mathrm{a}}$

\begin{tabular}{|c|c|c|c|c|c|}
\hline \multirow[b]{2}{*}{ Model } & \multicolumn{2}{|c|}{$\begin{array}{c}\text { Unstandardized } \\
\text { Coefficients }\end{array}$} & \multirow{2}{*}{$\begin{array}{l}\text { Standardized } \\
\text { Coefficients } \\
\text { Beta }\end{array}$} & \multirow[b]{2}{*}{$\mathrm{t}$} & \multirow[b]{2}{*}{ Sig. } \\
\hline & $\mathrm{B}$ & Std. Error & & & \\
\hline $\begin{array}{ll}1 & \text { (Constant) } \\
& \text { Karakteristik }\end{array}$ & $\begin{array}{r}12.640 \\
.259 \\
\end{array}$ & $\begin{array}{r}4.717 \\
.065\end{array}$ & .358 & $\begin{array}{l}2.680 \\
3.988\end{array}$ & $\begin{array}{l}.009 \\
.000\end{array}$ \\
\hline
\end{tabular}

Dari tabel 8 , diatas diperoleh nilai $\mathrm{t}_{\text {hitung }}$ sebesar 3.988. Penelitian ini menggunakan taraf signifikansi $(\alpha: 0,05)$ dan Derajat Kebebasan (DK) dengan ketentuan $\mathrm{DK}=\mathrm{n}-2$, atau $77-2=$ 75. Dengan ketentuan tersebut, diperoleh nilai $t_{\text {tabel }}$ sebesar 1.995. Dengan kriteria hipotesis sebagai berikut :

Jika $t_{\text {hitung }}>t_{\text {tabel }}$, maka $\mathrm{H}_{0}$ ditolak dan $\mathrm{H}_{\mathrm{a}}$ diterima.
Dasar (SD) Se-Kecamatan Stabat Kabupaten Langkat. Besarnya berpengaruh signifikan terhadap Kinerja Guru di Sekolah Dasar (SD) Se-Kecamatan Stabat Kabupaten Langkat sebesar 2.391 atau $23.9 \%$.

\section{c. Pengaruh Karakteristik Terhadap Kinerja \\ Guru di Sekolah Dasar ( SD ) Se- Kecamatan Stabat Kabupaten Langkat}

Untuk mengetahui pengaruh Karakterikstik kerja terhadap Terhadap Kinerja Guru di Sekolah Dasar ( SD ) Se-Kecamatan Stabat Kabupaten Langkat digunakan uji-t, sedangkan untuk melihat besarnya pengaruh digunakan angka Beta atau Standardized Coefficient.
Jika $\mathrm{t}_{\text {hitung }}<\mathrm{t}_{\text {tabel }}$, maka $\mathrm{H}_{0}$ diterima dan $\mathrm{H}_{\mathrm{a}}$ ditolak.

Dari hasil perhitungan diperoleh nilai $t_{\text {hitung }}>$ $\mathrm{t}_{\text {tabel }}(3.988>1.995)$ dan nilai signifikasi $0.000<$ 0.05 , sehingga $\mathrm{H}_{0}$ ditolak dan $\mathrm{Ha}$ diterima. Artinya variabel karakteristik berpengaruh signifikan terhadap Kinerja Guru di Sekolah Dasar (SD) Se-Kecamatan Stabat Kabupaten Langkat. Besarnya berpengaruh signifikan terhadap Kinerja Guru di Sekolah Dasar (SD) 
Se-Kecamatan Stabat Kabupaten Langkat sebesar 3.998 atau $39.98 \%$.

\subsubsection{Uji Determinasi $\left(\mathbf{R}^{2}\right)$}

Untuk melihat pengaruh Disiplin, Profesionalisme, Karakteristik Terhadap Kinerja

Tabel 9 Uji - F (Simultan)

Model Summary ${ }^{\mathrm{b}}$

\begin{tabular}{l|c|r|r|r|}
\hline Model & R & R Square & $\begin{array}{c}\text { Adjusted R } \\
\text { Square }\end{array}$ & $\begin{array}{c}\text { Std. Error of } \\
\text { the Estimate }\end{array}$ \\
\hline 1 & $.642^{\mathrm{a}}$ & .413 & .389 & 2.341 \\
\hline
\end{tabular}
a. Predictors: (Constant), Karakteristik, Disiplin, Profesionalisme
b. Dependent Variable: Kinerja

Besarnya angka Adjusted Rsquare $\left(\mathrm{r}^{2}\right)$ adalah 0.413. Angka tersebut mempunyai maksud bahwa pengaruh Disiplin, Profesionalisme, Karakteristik Terhadap Kinerja Guru di Sekolah Dasar ( SD ) Se-Kecamatan Stabat Kabupaten Langkat. sebesar $41.3 \%$, sedangkan sisanya sebesar 58.7\% (100\% - 41.3\%) dipengaruhi oleh faktor-faktor lain yang tidak diteliti. Dengan kata lain variabilitas kinerja guru dapat diterangkan oleh variabel disiplin, prfesionalisme dan karakteristik sebesar $41.3 \%$, sedangkan sisanya sebesar $58.7 \%$ disebabkan oleh variabel-variabel lain diluar model ini.

\section{Kesimpulan}

Berdasarkan pada analisis perhitungan di atas, maka kesimpulan dari hasil penelitian ini adalah :

a. Variabel disiplin berpengaruh signifikan terhadap Kinerja Guru di Sekolah Dasar (SD) Se-Kecamatan Stabat Kabupaten Langkat. Besarnya berpengaruh signifikan terhadap Kinerja Guru di Sekolah Dasar (SD) SeKecamatan Stabat Kabupaten Langkat dengan nilai $t_{\text {hitung }}>t_{\text {tabel }}(4.708>1.995)$.

b. Variabel profesionalisme berpengaruh signifikan terhadap Kinerja Guru di Sekolah Dasar (SD) Se-Kecamatan Stabat Kabupaten Langkat. Besarnya berpengaruh signifikan terhadap Kinerja Guru di Sekolah Dasar (SD) Se-Kecamatan Stabat Kabupaten Langkat dengan nilai $t_{\text {hitung }}>\mathrm{t}_{\text {tabel }}(2.391>1.995)$

c. Variabel karakteristik berpengaruh signifikan terhadap Kinerja Guru di Sekolah Dasar (SD) Se-Kecamatan Stabat Kabupaten Langkat. Besarnya berpengaruh signifikan terhadap Kinerja Guru di Sekolah Dasar (SD) SeKecamatan Stabat Kabupaten Langkat dengan nilai $t_{\text {hitung }}>t_{\text {tabel }}(3.988>1.995)$

d. Variabel Disiplin, Profesionalisme, Karakteristik berpengaruh Terhadap Kinerja Guru di Sekolah Dasar ( SD ) Se-Kecamatan
Guru di Sekolah Dasar ( SD ) Se-Kecamatan Stabat Kabupaten Langkat. maka dapat dilihat dari hasil perhitungan dalam model summary, khususnya angka Rsquare dibawah ini :
Stabat Kabupaten Langkat. sebesar 41.3\%, sedangkan sisanya sebesar $58.7 \%(100 \%$ 41.3\%) dipengaruhi oleh faktor-faktor lain yang tidak diteliti.

\section{DAFTAR PUSTAKA}

Arifin, Zainal. 2010. Penelitian Pendidikan Metode dan Paradigma Baru. Bandung : Remaja Rosda Karya.

Ardana, I Komang dkk. 2016. Manajemen Sumber Daya Manusia. Yogyakarta: Graha ilmu.

Arikunto, Suharsimi. 2010. Prosedur Penelitian Suatu Pendekatan Praktek. Jakarta : PT. Rineka Cipta.

Arikunto, Suharsimi. 2011. Prosedur Penelitian: Suatu Pendekatan Praktik. Edisi Revisi VII. Jakarta: PT. Rineka Cipta.

Barnawi dan Arifin. 2012. Etika dan Profesi Kependidikan. Jogjakarta : Ar-Ruzz Media.

Depdikbud. 2014 Tentang Standard Kompetensi Pendidikan. Jkarta : Puskur.Dit. PTKSD.

Dewi, Tiara Anggira. 2015. Pengaruh Profesionalisme Guru Dan Motivasi Kerja Terhadap Kinerja Guru Ekonomi SMA SeKota Malang. Jurnal.

Fattah, Nanang. 2010. Analisis Kebijakan Pendidikan. Bandung : PT. Remaja Rosdakarya.

Ghozali, Mohammad. 2013. Pengaruh Tingkat Kedisiplinan Kerja dan Budaya Organisasi Terhadap Kinerja Pegawai Pada Kantor Kementrian Agama Kab. Pasuruan. Jurnak ebook.

Gordon B. Davis. 2016. Kerangka Dasar: Sistem Informasi Manajemen, Bagian I Pengantar. Seri Manajemen No. 90-A. Cetakan Kedua Belas, Jakarta: PT. Pustaka Binawan Pressindo. 
Hamalik, Oemar, 2012. Manajemen Pengembangan Kurikulum. Bandung: PT. Remaja Rosda Karya.

Hunter, D.J \&Johnson V.L. 2014. The Epidemilogy of Osteoarthritis. Res Clinic Rheum. 28: 5-15.

Husna, Nikmatul. 2017. Pengaruh Disiplin Kerja Terhadap Kinerja Guru Pada SMAN 1 Canduang Kabupaten Agam. Jurnal.

Imran, Ali. 2015. Manajemen Sumber Daya Manusia. Jakarta : Pt. Rineka Cipta.

Jamal, Ma’mur Asmani. 2011. Buku Panduan Internalisasi Pendidikan Karakter di Sekolah. Jogjakarta: Diva Press.

Koestoer. 2013. Azas - Azas Manajemen. Yogyakarta : Kanisius.

Kunandar. 2014. Guru Profesional. Jakarta: Raja Grafindo Persada media.

Kurniawati. 2017. Ilmu dan Aplikasi Pendidikan. Bandung : Pt. Imperial Bhakti Utama.

Martono, Nanang. 2015. Metode Penelitian Kuantitatif Teori \& Aplikasi. Jakarta: Rajawali Pers.

Mathis, Robert L. dan John H. Jackson. 2012. Manajemen Sumber Daya Manusia, Edisi Pertama . Jakarta : Salemba Empat.

Mitchell, Richard. 2011. Robbins Basic Pathology. USA : McGraw Pers.

Mulyasa, E. 2011. Manajemen Berbasis Sekolah. Bandung : PT. Remaja Rosda Karya.

Nawawi, 2016. Manajemen Sumber Daya Manusia: Untuk Bisnis Yang Kompetitif, Gajahmada. Yogyakarta : University Press.

Nitisemito, Alex S. 2011, Manajemen Personalia. Jakarta : Ghalia Indonesia.

Peraturan Pemerintah. 2005. Tentang Standard Nasional Pendidikan.

Peraturan Pemerintah. 2018. Tentang Penilaian Kinerja Pegawai Negeri Sipil.

Prasetyo, Bambang, Lina Miftahul Jannah. 2018. Metode Penelitian Kuantitatif: Teori dan Aplikasi. Jakarta : PT Raja Grafindo Persada.

Purnomo, Ratno dan Sri Lestari. 2010. Pengaruh Kepribadian, Self-Efficacy, dan Locus Of Control Terhadap Persepsi Kinerja Usaha Skala Kecil dan Menengah. Jurnal Bisnis dan Ekonomi (JBE) Vol 17, (2), 144-160, ISSN: 1412-3126.

Rachmawati, Intan. 2014. Pengaruh Profesionalisme Guru Dan Karakteristik Guru Serta Kepemimpinan Kepala Sekolah Terhadap Kinerja Guru SMK Batik 1 Surakarta. Tesis.
Rahman, Agus. 2013. Psikologi Sosial: Integrasi Pengetahuan Wahyu dan Pengetahuan Empirik. Jakarta: Rajawali Pers.

Ridwan, Husein. 2015. Desain Penelitian Manajemen Stratejik. Jakarta : Rajawali Press.

Rif'ah, Wasiatul. 2016. Pengaruh Kedisiplinan, Profesionalisme Guru dan Karakteristik Individu Terhadap Kinerja Guru Di MTS Sultan Fatah Gaji Kecamatan Guntur Kabupaten Demak. Jurnal

Robbins, Stephen P. 2008. Perilaku Organisasi. Edisi Revisi. Jakarta : Gramedia.

Robbins, Stephen P. 2013. The Priciple of Organizational Behaviour. USA: Prentice Hall Inn.

Sagala, Syaiful. 2015. Konsep dan Makna Pembelajaran Untuk Membantu Memecahkan Problematika Belajar dan Mengajar. Bandung: Alfabeta.

Sedarmayanti. 2010. Sumber Daya Manusia dan Produktivitas Kerja, Cetakan Kedua. Bandung : Mandar Maju.

Simamora, Bilson. 2014. Riset Pemasaran Manajemen. Jakarta : Gramedia Utama.

Sirait. Afrida. 2010. Pengaruh Budaya Organisasi Terhadap Produktivitas Pegawai. Skripsi.

Siswanto. 2013. Pengantar Manajemen. Jakarta : PT. Bumi Aksara.

Soekartawi. 2015. Perinsip dasar Ilmu Manjemen. Jakarta : UI Press.

Sofyandi dan Garniwa. 2017. Perilaku Organisasional. Edisi Revisi. Yogyakarta : Graha Ilmu.

Sudjana. 2012. Metode Statistika. Bandung : Tarsito.

Sugiyono. 2010. Metode Penelitian Bisnis Cetakan kesembilan. Bandung : Alfabeta.

Sugiyono. 2014. Metode Penelitian Pendidikan Pendekatan Kuantitatif, Kualitatif dan R\&D. Bandung : Alfabeta.

Sumodiningrat, Gunawan. 2001. Menejemen Pendidikan. Yogyakarta : Pustaka Pelajar.

Supardi. 2014. Kinerja Guru. Jakarta : PT. Raja Grafindo Persada.

Supeno, Minto. 2015. Manjemen Sumber Daya Manusia : Suatu Paradigma Baru. Jakarta : Galileo Indonesia.

Surya Dharma. 2015. Manajemen Kinerja Falsafah teori dan penerapannya. Yogyakarta : Pustaka Pelajar.

Sutjipto. 2013. Media Pembelajaran Yang Efektif. Jakarta : Erlangga.

Sutrisno, Agus. 2012. Etika Manajemen. Jakarta : Graha Ilmu. 
Thoha, Miftah. 2012. Prilaku Organisasi, Konsep Dasar Dan Implikasinya. Jakarta : Pt. Raja Grafindo Persada.

Umiarso \& Gojali Imam. 2010. Manajemen Mutu Sekolah di Era Otonomi Pendidikan. Yogyakarta : IRCiSoD

Undang - Undang Republik Indonesia Nomor 20 Tahun 2003 Tentang Sistem Pendidikan Nasional. Jakarta : Dharma Bakti.

Usman, Husaini. 2012. Manajemen dan Riset Pendidikan, Edisi Keempat. Jakarta : Bumi Aksara.

Yusrizal. 2018. Manajemen Pendidikan. Jakarta : Bumi Aksara. 